Çukurova Üniversitesi Mühendislik Mimarlık Fakültesi Dergisi, 31(ÖS 2), ss. ÖS 117-ÖS 125, Ekim 2016

Çukurova University Journal of the Faculty of Engineering and Architecture, 31(SI 2), pp. SI 117-SI 125, October 2016

\title{
Refrakter Tuğlaların Teknolojik Özelliklerinin İncelenmesi
}

\author{
Özen KILIÇ ${ }^{* 1}$, Selin YARBİL ${ }^{1}$ \\ ${ }^{1}$ Çukurova Üniversitesi, Mühendislik Mimarlık Fakültesi, Maden Mühendisliği Bölümü, Adana
}

Geliş tarihi: 03.09.2016 Kabul tarihi: 03.10.2016

$\ddot{\mathbf{O} z}$

Yapılan çalışmada bazı refrakter hammaddelerin farklı oranlarda karıştırılması ile elde edilen refrakter tuğlaların özellikleri incelenmiştir. İnceleme Remsan A.Ş.'nin kullandığı hammaddeler ve bu hammaddelerden üretilen refrakter tuğlalar üzerinde yoğunlaştırılmıştır. İlk aşamada, refrakter tuğla bünyesine giren bazı hammaddelerin kimyasal ve mineralojik özellikleri belirlenmiştir. Ardından değişik oranlarda refrakter hammaddeler ve katkılar kullanılarak Remsan A.Ş. tarafindan üretilen refrakter tuğlaların kimyasal, mineralojik ve teknolojik özellikleri belirlenmiş̧ir.

İncelemeler sonunda, refrakter tuğlaların bileșimlerine giren malzemelere bağlı olarak farklı sıcaklıklarda kullanılabilir olduğu ve dayanımlarının değişiklik gösterdiği anlaşılmıştır.

Anahtar Kelimeler: Refrakter tuğla, Kimyasal özellik, Mineralojik özellik, Teknik özellikler

\section{Investigation of Technological Properties of Refractory Bricks}

\begin{abstract}
In this study, the properties of refractory bricks obtained by mixing some refractory raw materials at different ratios were examined. The examination is focused on the raw materials used by REMSAN Inc. and the produced refractory bricks. Firstly, chemical and mineralogical properties of some raw materials kind of refractory bricks are determined. Then, chemical, mineralogical and technological properties of refractory bricks which using different proportions of refractory raw materials and additives produced by Remsan Inc. were determined.
\end{abstract}

At the end of the tests, it is shown that the refractory bricks can be used in different temperatures and have different endurances according to materials contained.

Keywords: Refractory brick, Chemical property, Mineralogical property, Technological properties

*Sorumlu yazar (Corresponding author): Özen KILIÇ, zenkilic@cu.edu.tr 


\section{GíRiș}

Refrakterler, ateşe dayanıklı malzemeler olarak tanımlanır. Refrakter malzemeler $1000^{\circ} \mathrm{C}$ 'nin üzerindeki sıcaklıklarda uzun süre kullanılabilirler $[1,2]$. Refrakter malzemeler 1sıya dayanıklı oldukları için 1s1 geçirmeyen malzemelerdir. Yakma ortamlarında refrakter malzeme kullanılması durumunda 1sı geçişi/kaçışı en az olmakta; yakıt tasarrufu sağlanmakta ve buna bağlı olarak da karbondioksit oluşumu azalmaktadır.

Refrakter killer refrakter sanayiinin ana hammaddesini teşkil eder. Kullanımları günden güne artmakta ve özellik arzeden yeni kullanım alanları da gelişmektedir [3,4]. Çoğu zaman refrakter malzemenin görevi yüksek sıcaklıklı reaksiyon ortamını dıştan perdelemek ya da mufl firınlarda aksine olarak sıcak ortamdaki ısıyı firın içerisine taşımak olabilir. Yapısal düzenlerinden dolayı camların 1sı iletme katsayıları özgül ısıya göre değişir ve 1sı iletme kabiliyeti sıcaklık yükseldikçe artar. Bu karakteristik cam fazlı ateşe dayanıklı malzemelerde az ya da çok etkili olur. Hafif tuğlada olduğu gibi çok büyük gözeneklere sahip malzemelerde gözenek cidarları radyasyon alışverişine iştirak ettiklerinden dolayı 1sı iletme kabiliyetlerinde yükselme gösterirler.

Sıcaklık değişimlerine dayanım ısıl şok dayanım olarak tanımlanır. İşletme esnasında 1sıtma ve soğutma veya sıcaklık salınımları malzemenin yüzeyi ve merkezi arasında sıcaklık farkları ve bunun sonucu olarak da genleşme gerilmeleri meydana getirir. Bir cisim her tarafindan soğutulduğunda yüzey boyunca çekme gerilmeleri ve merkezinde basma gerilmeleri meydana gelir. Oluşan isıl gerilmeler, malzemenin dayanımını aşarsa çatlaklar meydana getirerek malzemenin parçalanmasına neden olur. S1caklığın yükselmesi ile katı hacimde meydana gelen genişleme ile birlikte gözeneklilik azalır. Gözenekliliğin azalması ile refrakter malzeme yumuşar. $\mathrm{Bu}$ özellik malzemenin karakterini tayin eder. Gözenekliliğin azalmasıyla orantılı olarak yoğunlukta artış görülür. Refrakter malzemenin yoğunluğunun erime sırasında değişimi büyük önem taşır. Erime olayı ile birlikte hacim değişir ve malzemenin fiziksel özelliklerinde büyük sapmalar olur.

Refrakter malzemelerin en önemli özelliği yük altında şekil değiştirmeye karşı göstermiş oldukları dirençtir. Refrakter malzemelerin soğukta basınç dayanımına malzemenin yapısı ve özellikle gözenek miktarı etkir. Ateşe dayanıklı tuğlalar oda sıcaklığında pek az şekil değiştirme gösterirler. Yüksek sicaklıkta farklı tane büyüklüğü ve gözenek dağılımı ile yapıdaki değişik fazların arasındaki gerilmeler nedeniyle çatlaklar oluşabilir. Kural olarak cam fazının miktarının yükselmesiyle dayanım artar. Fırın içerisinde kullanım için bu yeterli olmaktadır. Taşıma esnasında kayıpları önlemek için dayanım en az 3 $\mathrm{MPa}$ olmalıdır. Mekanik dayanım ve aşınma direnci yaklaşık $1000^{\circ} \mathrm{C}^{\prime}$ ye kadar durumunu muhafaza eder. Daha yüksek sıcaklıklarda cam fazının artmasıyla birlikte aşınma dayanımı azalır [5,6] (Çizelge 1).

Çekme olayının meydana gelmesi genellikle malzemenin üretim sirasında yeterli derecede pişmemesinden veya refrakter özelliğinin olmayışından ileri gelir. Genişleme nedeni ise malzemenin yapıldı ̆̆ 1 hammaddenin parça büyüklügüünun yetersiz olmasındandır.

Çizelge 1. Bazı refrakter tuğlaların önemli özellikleri [5,6]

\begin{tabular}{|l|c|c|c|c|}
\hline Malzeme türü & Soğukta basma dayanımı $(\mathrm{MPa})$ & Elastiklik modülü $(\mathrm{GPa})$ & Poisson sabiti & Yoğunluk \\
\hline Silika tuğla & $15-50$ & $11-25$ & $0,6-0,25$ & $1,8-2,2$ \\
\hline Şamot tuğla & $13-60$ & $24-30$ & $0,20-0,40$ & $1,8-2,2$ \\
\hline Periklas tuğla & $30-100$ & $110-140$ & $0,19-0,30$ & $2,8-3,3$ \\
\hline SíC tuğla & $30-90$ & - & - & $2,3-2,8$ \\
\hline Karbon tuğla & $20-60$ & $12-13$ & $0,21-0,23$ & $1,3-1,6$ \\
\hline Ateş tuğlası & $3-10$ & $2-8$ & $0,12-0,17$ & $0,4-1,2$ \\
\hline $\mathrm{Al}_{2} \mathrm{O}_{3}$ & $196-300$ & $240-400$ & $0,2-0,3$ & $3,3-3,6$ \\
\hline
\end{tabular}


Şamot ve magnezit tuğlalar üretimleri sırasında daralma, silika tipi tuğlalar genişleme gösterir. Fazla miktarda hacim değişimi çatlamalara neden olur.

Refrakter malzemeler elektriği iyi iletmezler, yük altında kırılgandır, ergime noktaları yüksektir mikro ve makro yapıda heterojendir.

Fırın tipi, üretim teknolojisi ve üretim cinsine göre firınlarda uygulanan prosesler değişmekte ve her değişen proses, değişik tür ve özelliklerde refrakter kullanmayı gerektirmektedir. $\mathrm{Bu}$ nedenle çok değişik refrakterler üretilmektedir.

Yapılan çalışma kapsamında, ilk aşamada refrakter tuğla üretiminde kullanılan malzemelerin kimyasal ve mineralojik özellikleri; ardından hammaddeler ve değişik katkı maddeleri kullanılarak üretilen tuğlaların kimyasal, mineralojik ve teknolojik özellikleri analizler ve deneyler ile belirlenmeye çalışılmıştır.

\section{MATERYAL VE METOD}

İncelenen refrakter numuneleri REMSAN A.S. (İstanbul)'nin kullandığ 1 hammaddelerden ve bu hammaddelerle yapılan refrakter tuğlalardan seçilmiştir. Örnekler üzerine uygulanan deneyler REMSAN A.Ş. ve Çukurova Üniversitesi Maden Mühendisliği Bölümü laboratuarlarında yapılmıştır. Yapılan çalışmalarda, farklı hammaddelerin ve bu hammaddelerden farklı oranlarda karıştırılarak üretilen refrakter tuğlaların özellikleri incelenmiştir [7].

Tuğlalar, farklı bileşimlerdeki refrakter hammaddelerin değişik oranlarda karıştırıcıda ortalama \%6 su ilavesi ile yaklaşık 2-3 dakika karıştırılması ile elde edilmiş harçtan üretilmiştir. Yeterince karıştırılan karışım vibrasyonlu masalarda yer alan $75 \times 75 \times 75 \mathrm{~mm}$ boyutlarındaki kalıplara dökülmüş etiketlenerek priz süresinin tamamlanması beklenmiştir. Tuğlalar donduktan sonra kalıplarından sökülerek farklı sıcaklıklardaki firında pişirilmiştir. Fırından çıkan pişmiş tuğlalar soğuduktan sonra tuğla özelliklerini belirleme deneylerine tabi tutulmuştur.
Deneysel çalışmalarda kullanılan refrakter tuğlaların üretiminde kullanılan hammaddelerin isimleri, ticari olması nedeni ile açıça verilmeyerek kodlarla gösterilmiştir. Refrakter tuğlalar ise Remsan A.Ş.'nin kullandığı isimleri ile belirtilmiştir. Şirket sırrı olması nedeni ile yapılan çalışma kapsamında refrakter tuğlaların üretiminde kullanılan hammadde karışım oranları da belirtilmemektedir. Refrakter tuğla bileşimine giren hammaddelerin neler olduğu yapılan kimyasal ve mineralojik analizler ile belirlenmeye çalışılmış; hammaddeler ve değişik katkı maddeleri kullanılarak üretilen tuğlaların kimyasal, mineralojik, mekanik ve teknolojik özellikleri yapılan analizler ve deneyler ile anlaşılmaya, belirlenmeye çalışılmıştır.

Refrakter örneklerinin kimyasal analizleri XRF (Siemens SRS 300 X-ray Fluoresans Spectrometer) kullanılarak, mineralojik tanımlama kalitatif ve yarı kalitatif analiz yöntemi (XRD) Rigaku Minflex 2 ile ve sonik hız ölçümü (P dalgası) pundit cihazı (CNS Farnel Pundit Plus C) ile yapılmıştır.

\section{ARASTIRMA BULGULARI}

\subsection{Toz Haldeki Numuneler}

\subsubsection{Kimyasal Analiz}

Remsan A.Ş.'den getirilen refrakter tuğla yapımında kullanılan toz haldeki bazı hammaddelerin kimyasal analizleri XRF yöntemi ile yapılmış ve analiz sonuçları Çizelge 2'de verilmiştir. Kimyasal analizi yapılan örneklerin kimyasal bileşimleri göz önüne alındığında 1 nolu örneğin kil veya şamot tuğla (ateşe dayanıklı killerden elde edilir. Bu killer alkali, toprak alkali, muskovit veya mika içerebilir), 2 nolu örneğin silika, 3 ve 4 nolu örneklerin yüksek $\mathrm{Al}_{2} \mathrm{O}_{3}$ bileşimine sahip olması nedeniyle korundum veya korund tuğla $\left(1700^{\circ} \mathrm{C}\right.$ ve üzeri sıcaklıklarda sıv1 gaz miktarı düşerek kristal oluşumu sağlanır; yük altında refrakterlik artar) ve 5 nolu örneğin boksit veya disten (boksit ve disten bileşim olarak \%40-55 $\mathrm{Al}_{2} \mathrm{O}_{3}$ ihtiva eden bir mineraldir) olduğu düşünülmektedir. 
Çizelge 2. Toz halindeki örneklerin kimyasal analiz sonuçları (\%)

\begin{tabular}{|c|c|c|c|c|c|c|}
\hline Örnek & $\mathrm{Al}_{2} \mathrm{O}_{3}$ & $\mathrm{SiO}_{2}$ & $\mathrm{CaO}$ & $\mathrm{TiO}_{2}$ & $\mathrm{Fe}_{2} \mathrm{O}_{3}$ & $\mathrm{~K}_{2} \mathrm{O}$ \\
\hline 1 & 34,10 & 58,54 & 0,304 & 1,112 & 3,070 & 1,790 \\
\hline 2 & 1,260 & 96,67 & - & 0,013 & 0,1054 & - \\
\hline 3 & 98,76 & 0,18 & 0,108 & 0,013 & 0,020 & - \\
\hline 4 & 96,47 & - & 0,066 & 0,380 & 0,0335 & - \\
\hline 5 & 43,20 & 52,53 & 0,379 & - & 1,562 & - \\
\hline
\end{tabular}

\subsection{Mineralojik Analiz}

Mineralojik analiz için XRD cihazı ile çekilen paternler incelendiğinde 1 nolu örneğin kil, 2 nolu örneğin silika, 3 nolu örneğin kil katkılı korund, 4 nolu örneğin boksit katkılı korund ve 5 nolu örneğin boksit olabileceği düşünülmektedir. İncelenen örnekler ve eklenecek katkılar değişik oranlarda karıştırılarak refrakter tuğla üretimi için uygun harçlar oluşturulmasına olanak sağlanabilecektir.

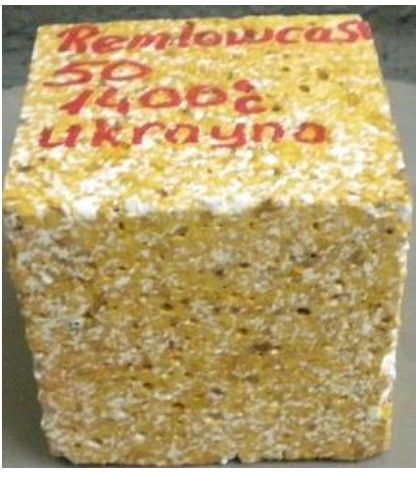

a

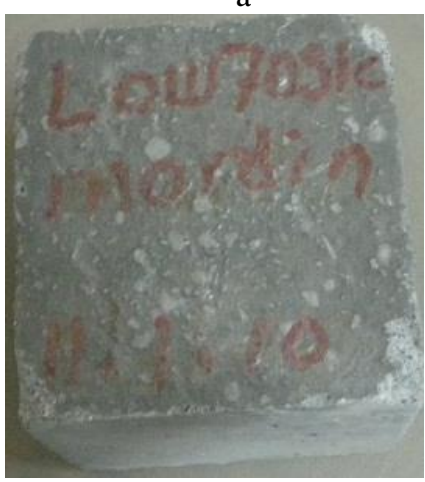

d

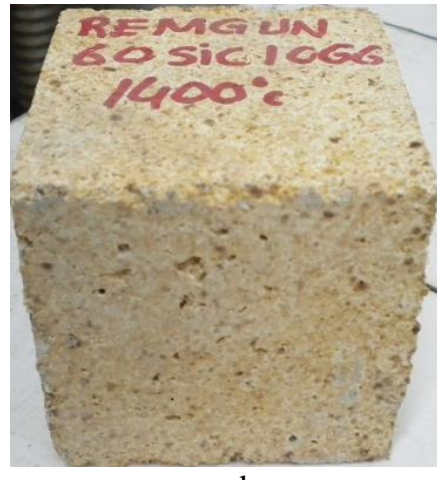

b

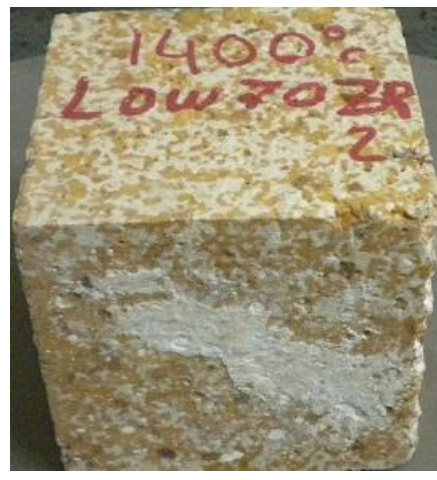

e

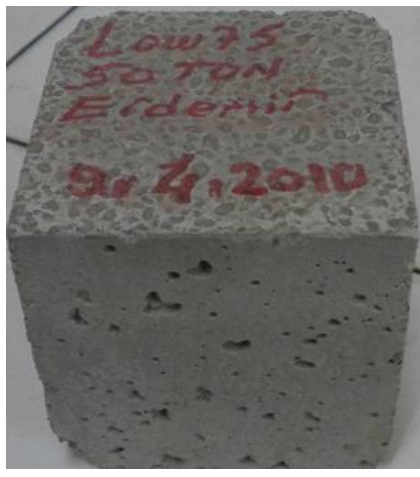

$\mathrm{c}$

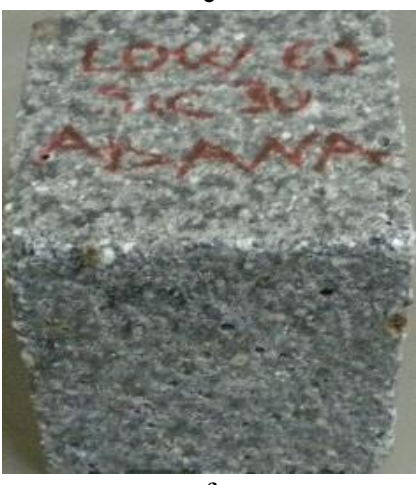

f

Şekil 1. İncelenen refrakter tuğlaların görüntüsü (a. Remlowcast 50 vibration castable, b. Remgun 60 SİC 10 GG gunning, c. Remlowcast 75 vibration castable, d. Remlowcast 70 SİC vibration castable, e. Remlowcast $70 \mathrm{Zr}$ vibration castable, f. Remlowcast 60 SİC 30 vibration castable) 


\subsubsection{Kimyasal Analiz}

Remsan A.Ş.'den getirilen altı farklı refrakter tuğlanın kimyasal analizleri XRF yöntemi ile yapılmış ve analiz sonuçları Çizelge 3'de verilmiştir. İncelenen refrakter tuğlaların $>\% 50$ $\mathrm{Al}_{2} \mathrm{O}_{3}$ ihtiva etmesi nedeni ile sicaklık şoklarına dayanabilecek yüksek mukavemete sahip olacağ1 $\mathrm{Fe}_{2} \mathrm{O}_{3}$ oranının düşük olması ile de tuğlaların erozyon ve aşınmaya karşı yüksek mukavemet sergileyeceği düşünülmektedir. $\mathrm{Al}_{2} \mathrm{O}_{3}$ oran1 fazla olan bileşenlerden üretilen tuğlaların dayanım değerinin ise yüksek olacağ 1 düşünülmektedir.

Çizelge 3. Refrakter tuğlaların kimyasal analiz sonuçları (\%)

\begin{tabular}{|l|c|c|c|c|c|c|c|c|}
\hline \multicolumn{1}{|c|}{ Örnek } & $\mathrm{Al}_{2} \mathrm{O}_{3}+\mathrm{TiO}_{2}$ & $\mathrm{SiO}_{2}$ & $\mathrm{Fe}_{2} \mathrm{O}_{3}$ & $\mathrm{CaO}$ & $\mathrm{MgO}$ & $\mathrm{ZrO}_{2}$ & $\mathrm{SIC}$ & $\mathrm{Alkali}$ \\
\hline Remlowcast 50 vibration castable & 51 & 44,8 & 1,2 & 1,9 & 0,1 & - & - & 0,6 \\
\hline Remgun 60 SİC 10 GG gunning castable & 59,6 & 20,2 & 0,8 & 4,9 & - & - & 14 & 0,2 \\
\hline Remlowcast 75 vibration castable & 75,9 & 20 & 1,3 & 1,7 & - & - & - & 0,4 \\
\hline Remlowcast 70 SİC vibration & 29 & 9,2 & 0,2 & 1,8 & 0,1 & & 59,5 & 0,1 \\
\hline Remlowcast 70 Zr vibration castable & 71 & 19,9 & 1,5 & 1,6 & - & 5,7 & & 0,1 \\
\hline Remlowcast 60 SİC 30 vibration & 39,7 & 26 & 0,62 & 1,8 & - & - & 31 & - \\
\hline
\end{tabular}

\subsubsection{Mineralojik Analiz}

Refrakter tuğla örneklerinin mineralojik analizleri Ç.Ü. Maden Mühendisliği Bölümü laboratuarında bulunan XRD cihazı ile gerçekleştirilmiş ve elde edilen XRD paterni sonuçlarının incelenmesinden; Remlowcast 50 vibration castable'in mullit, anortit,

Remgun 60 SİC 10 GG gunning'in anortit, korundum, mullit, andalusit,

Remlowcast 75 vibration castable'ın sillimanit, ilvait,

Remlowcast 70 SİC vibration castable'ın mullit, Remlowcast $70 \mathrm{Zr}$ vibration castable'in mullit ve Remlowcast 60 SİC 30 vibration castable'in andalusit ve mullit minerallerinden oluştuğu belirlenmiştir.
Mineralojik inceleme sonuçlarına göre refrakter tuğlalarda kil grubu minerallerin hakim olduğu ve incelenen örneklerin yüksek sıcaklıklara kolayca dayanan iyi kalite refrakterler grubunda olacak şekilde üretildiği anlaşılmıştır.

\subsection{3. İncelenen Refrakter Tuğlaların Özellikleri}

\subsubsection{Remlowcast 50 Vibration Castable}

$75 \times 75 \times 75$ mm'lik kalıplara döküldükten sonra pişirilen Remlowcast 50 vibration castable refrakter tuğla numunesinin fizikomekanik özellikleri Çizelge 4'de ve teknik özellikleri ise Çizelge 5'de verilmiştir.

Çizelge 4. Remlowcast 50 vibration castable numunesinin fizikomekanik özellikleri

\begin{tabular}{|c|c|c|c|c|}
\hline $\begin{array}{c}\text { Sicaklık } \\
\left({ }^{\circ} \mathrm{C}\right)\end{array}$ & $\begin{array}{c}\text { Kirılma Modülü } \\
\left(\mathrm{kg} / \mathrm{cm}^{2}\right)\end{array}$ & $\begin{array}{c}\text { Basma Mukavemeti } \\
\left(\mathrm{kg} / \mathrm{cm}^{2}\right)\end{array}$ & $\begin{array}{c}\text { Kalıc1 Boyutsal } \\
\text { Değişme }(\%)\end{array}$ & $\begin{array}{c}\text { Termal Kondüktivite } \\
\left(\mathrm{kcal} /{ }^{\circ} \mathrm{C} . \mathrm{h} . \mathrm{m}\right)\end{array}$ \\
\hline 110 & 105 & 660 & - & - \\
\hline 820 & 110 & 700 & $+0,1$ & - \\
\hline 1100 & 138 & 720 & $+0,2$ & 0,65 \\
\hline 1250 & 160 & 800 & $+0,2$ & 0,7 \\
\hline 1400 & 190 & 1000 & $-0,2$ & - \\
\hline 1500 & 200 & 1100 & - & 0,8 \\
\hline
\end{tabular}

Remlowcast 50 vibration castable numunesi içerisindeki $\mathrm{Al}_{2} \mathrm{O}_{3}$ miktarı $\% 50$ olan düşük çimentolu, vibrasyon uygulamalı beton refrakterdir. Yüksek yoğunluklu, düşük poroziteli ve çok yüksek mukavemet değerlerine sahip bir malzeme olmasının nedeninin bünyesindeki su 
miktarının az olması olduğu düşünülebilir. $\mathrm{Fe}_{2} \mathrm{O}_{3}$ oranının düşük olması nedeni ile erozyon ve aşınmaya karşı yüksek mukavemete sahiptir. Yük altında sıcakta deformasyonun az olması istenen yerlerde kullanımı uygundur. Remlowcast 50 vibration castable $110-1550^{\circ} \mathrm{C}$ aras 1 servis sıcaklığına sahiptir.

Çizelge 5. Remlowcast 50 vibration castable numunesinin teknik özellikleri

\begin{tabular}{|l|c|}
\hline Servis sıcaklığı & $1550^{\circ} \mathrm{C}$ \\
\hline Yumuşama sıcaklı̆̆ı & $36^{\circ} \mathrm{C}$ \\
\hline Kuru malzeme ihtiyacı & $2,3 \mathrm{~kg} / \mathrm{dm}^{3}$ \\
\hline Katılacak su miktarı & $\% 6$ en fazla \\
\hline $816^{\circ} \mathrm{C}$ 'de Porozite & 17,5 \\
\hline Çalışma süresi & 90,120 dakika en fazla \\
\hline
\end{tabular}

\subsubsection{Remgun 60 Síc 10 GG Gunning Castable}

$75 \times 75 \times 75$ mm'lik kalıplara döküldükten sonra $1400^{\circ} \mathrm{C}$ 'de pişirilen Remgun 60 SíC $10 \mathrm{GG}$ gunning castable refrakter tuğla numunesinin fizikomekanik özellikleri Çizelge 6'da ve teknik özellikleri ise Çizelge 7'de verilmiştir.

İçeriğinde $\% 58 \mathrm{Al}_{2} \mathrm{O}_{3}$ ihtiva eden Remgun $60 \mathrm{SİC}$ 10 GG gunning castable yapida bir betondur. Fırında $1400^{\circ} \mathrm{C}^{\prime}$ de pişirilerek refrakter tuğla haline getirilmiştir. İçerisine silicon carbide eklenerek çok yüksek yapışma ve yüksek mukavemetli olması sağlanmıştır. $110-1400^{\circ} \mathrm{C}$ arası servis sıcaklığına sahiptir.

Çizelge 6. Remgun 60 SİC 10 GG gunning castable numunesinin fizikomekanik özellikleri

\begin{tabular}{|c|c|c|c|c|}
\hline $\begin{array}{c}\text { Sicaklık } \\
\left({ }^{\circ} \mathrm{C}\right)\end{array}$ & $\begin{array}{c}\text { Krrılma Modülü } \\
\left(\mathrm{kg} / \mathrm{cm}^{2}\right)\end{array}$ & $\begin{array}{c}\text { Basma Mukavemeti } \\
\left(\mathrm{kg} / \mathrm{cm}^{2}\right)\end{array}$ & $\begin{array}{c}\text { Kalıcı Boyutsal } \\
\text { Değişme }(\%)\end{array}$ & $\begin{array}{c}\text { Termal Kondüktivite } \\
\left(\mathrm{kcal} /{ }^{\circ} \mathrm{C} . h . \mathrm{m}\right)\end{array}$ \\
\hline 110 & 95 & 360 & - & - \\
\hline 820 & 68 & 200 & $-0,1$ & 1,2 \\
\hline 1100 & 69 & 250 & $-0,2$ & 1,05 \\
\hline 1400 & 95 & 300 & $-0,5$ & - \\
\hline
\end{tabular}

Çizelge 7. Remgun 60 SİC 10 GG gunning castable numunesinin teknik özellikleri

\begin{tabular}{|l|c|}
\hline Servis sıcaklığı & $1450^{\circ} \mathrm{C}$ \\
\hline Yumuşama sıcaklığı & $35^{\circ} \mathrm{C}$ \\
\hline Kuru malzeme ihtiyacı & $2,4 \mathrm{~kg} / \mathrm{dm}^{3}$ \\
\hline Katılacak su miktarı & en fazla $\% 12$ \\
\hline
\end{tabular}

\subsubsection{Remlowcast 75 Vibration Castable}

$75 \times 75 \times 75$ mm'lik kalıplara döküldükten sonra $820^{\circ} \mathrm{C}$ 'de pişirilen Remlowcast 75 vibration castable refrakter tuğla numunesinin fizikomekanik özellikleri Çizelge 8'de ve teknik özellikleri ise Çizelge 9'da verilmiştir.
Remlowcast 75 vibration castable numunesi bileşiminde en az $\% 75 \quad \mathrm{Al}_{2} \mathrm{O}_{3}$ içeren düşük çimentolu, özellikle vibrasyonlu dökümlerde kullanılan bir malzemedir.

Bünyesindeki su miktarının çok düşük olması nedeni ile yüksek yoğunluğa, düşük poroziteye ve diğer numunelere göre yüksek mukavemete sahiptir. $\mathrm{Fe}_{2} \mathrm{O}_{3}$ oranının düşük olması nedeni ile erozyon ve aşınmaya karşı yüksek mukavemete sahiptir ve yük altında sıcakta deformasyonun en az olması istenen yerlerde kullanımı uygundur. $110-1600^{\circ} \mathrm{C}$ arası servis sicaklığına sahiptir.

Çizelge 8. Remlowcast 75 vibration castable numunesinin fizikomekanik özellikleri

\begin{tabular}{|c|c|c|c|c|}
\hline $\begin{array}{c}\text { Sicaklık } \\
\left({ }^{\circ} \mathrm{C}\right)\end{array}$ & $\begin{array}{c}\text { Kirılma Modülü } \\
\left(\mathrm{kg} / \mathrm{cm}^{2}\right)\end{array}$ & $\begin{array}{c}\text { Basma Mukavemeti } \\
\left(\mathrm{kg} / \mathrm{cm}^{2}\right)\end{array}$ & $\begin{array}{c}\text { Kalıcı Boyutsal } \\
\text { Değişme }(\%)\end{array}$ & $\begin{array}{c}\text { Termal Kondüktivite } \\
\left(\mathrm{kcal} /{ }^{\circ} \mathrm{C} . \mathrm{h} . \mathrm{m}\right)\end{array}$ \\
\hline 110 & 120 & 650 & - & - \\
\hline 820 & 160 & 750 & $-0,18$ & 0,980 \\
\hline 1100 & 170 & 1100 & $-0,21$ & 0,95 \\
\hline 1400 & 180 & 1200 & 0,4 & 1,05 \\
\hline 1600 & 140 & 1250 & 0,15 & 1,15 \\
\hline
\end{tabular}


Çizelge 9. Remlowcast 75 vibration castable numunesinin teknik özellikleri

\begin{tabular}{|l|c|}
\hline Servis sıcaklı̆̆ 1 & $1760^{\circ} \mathrm{C}$ \\
\hline Yumuşama sıcaklığ 1 & $39^{\circ} \mathrm{C}$ \\
\hline Kuru malzeme ihtiyacı 1 & $2,5 \mathrm{~kg} / \mathrm{dm}^{3}$ \\
\hline Katılacak su miktarı & $\% 5$ en fazla \\
\hline $816^{\circ} \mathrm{C}$ 'de porozite & 18,7 \\
\hline Çalışma süresi & en fazla 90,120 dakika \\
\hline
\end{tabular}

\subsubsection{Remlowcast 70 SİC Vibration Castable}

$75 \times 75 \times 75$ mm'lik kalıplara döküldükten sonra $1100^{\circ} \mathrm{C}$ 'de pişirilen Remlowcast 70 SİC vibration castable refrakter tuğla numunesinin fizikomekanik özellikleri Çizelge 10'da ve teknik özellikleri ise Çizelge 11'de verilmiştir.

Çizelge 10. Remlowcast 70 SİC vibration castable numunesinin fizikomekanik özellikleri

\begin{tabular}{|c|c|c|c|c|}
\hline $\begin{array}{c}\text { Sicaklık } \\
\left({ }^{\circ} \mathrm{C}\right)\end{array}$ & $\begin{array}{c}\text { Kırılma Modülü } \\
\left(\mathrm{kg} / \mathrm{cm}^{2}\right)\end{array}$ & $\begin{array}{c}\text { Basma Mukavemeti } \\
\left(\mathrm{kg} / \mathrm{cm}^{2}\right)\end{array}$ & $\begin{array}{c}\text { Kalıcı Boyutsal } \\
\text { Değişme }(\%)\end{array}$ & $\begin{array}{c}\text { Termal Kondüktivite } \\
\left(\mathrm{kcal} /{ }^{\circ} \mathrm{C} . \mathrm{h} . \mathrm{m}\right)\end{array}$ \\
\hline 110 & 129,5 & 760 & - & - \\
\hline 820 & 176,5 & 1500 & $-0,18$ & - \\
\hline 1100 & 230 & 1300 & -0.21 & 6,98 \\
\hline 1200 & 248 & 1200 & 0,15 & - \\
\hline 1350 & 263 & 1300 & 0,45 & 6 \\
\hline
\end{tabular}

Çizelge 11. Remlowcast 70 SİC vibration castable numunesinin teknik özellikleri

\begin{tabular}{|l|c|}
\hline Servis sıcaklı̆̆ 1 & $1400^{\circ} \mathrm{C}$ \\
\hline Yumuşama sıcaklığ 1 & $30^{\circ} \mathrm{C}$ \\
\hline Kuru malzeme ihtiyacı & $2,6 \mathrm{~kg} / \mathrm{dm}^{3}$ \\
\hline Katılacak su miktarı & $\% 4-4,5$ \\
\hline $816^{\circ} \mathrm{C}$ 'de porozite & 18,7 \\
\hline Çalışma süresi & en fazla 90,120 dakika \\
\hline
\end{tabular}

Remlowcast 70 SIC vibration castable numunesi bileşimine \%59,5 SİC eklenen düşük çimentolu bir malzemedir. Yüksek yoğunluklu, düşük poroziteli ve çok yüksek mukavemet değerlerine sahip bir malzemedir. $\mathrm{Fe}_{2} \mathrm{O}_{3}$ oranı düşük olduğu için erozyon ve aşınmaya karşı yüksek mukavemet sahiptir. $\quad 110-1350^{\circ} \mathrm{C}$ arası servis sicaklığına sahiptir.

\subsubsection{Remlowcast $70 \mathrm{Zr}$ Vibration Castable}

$75 \times 75 \times 75$ mm'lik kalıplara döküldükten sonra $1400^{\circ} \mathrm{C}$ 'de pişirilen Remlowcast $70 \mathrm{Zr}$ vibration castable refrakter tuğla numunesinin fizikomekanik özellikleri Çizelge 12'de ve teknik özellikleri ise Çizelge 13'de verilmiştir.

Remlowcast $70 \mathrm{Zr}$ vibration castable numunesi $\% 70 \mathrm{Al}_{2} \mathrm{O}_{3}$ ihtiva ettiği için diğer numunelere göre yüksek mukavemete sahiptir. Yüksek yoğunluklu ve düşük porozitelidir. $\mathrm{Fe}_{2} \mathrm{O}_{3}$ oranı düşük olduğu için erozyon ve aşınmaya karşı yüksek mukavemet gösterir ve yük altında sıcakta deformasyonun minimum olması istenen yerlerde kullanımı uygundur. $110-1350^{\circ} \mathrm{C}$ arası servis sıcaklığına sahiptir.

Çizelge 12. Remlowcast $70 \mathrm{Zr}$ vibration castable numunesinin fizikomekanik özellikleri

\begin{tabular}{|c|c|c|c|c|}
\hline $\begin{array}{c}\text { Sicaklık } \\
\left({ }^{\circ} \mathrm{C}\right)\end{array}$ & $\begin{array}{c}\text { Krrılma Modülü } \\
\left(\mathrm{kg} / \mathrm{cm}^{2}\right)\end{array}$ & $\begin{array}{c}\text { Basma Mukavemeti } \\
\left(\mathrm{kg} / \mathrm{cm}^{2}\right)\end{array}$ & $\begin{array}{c}\text { Kalıcı Boyutsal } \\
\text { Değişme }(\%)\end{array}$ & $\begin{array}{c}\text { Termal Kondüktivite } \\
\left(\mathrm{kcal} /{ }^{\circ} \mathrm{C} . \mathrm{h} . \mathrm{m}\right)\end{array}$ \\
\hline 110 & 129,5 & 750 & - & - \\
\hline 820 & 176,5 & 850 & $-0,18$ & 0,98 \\
\hline 1100 & 180 & 860 & 0,2 & 1,05 \\
\hline 1400 & 195 & 1010 & 0,3 & 1,1 \\
\hline 1600 & 200 & 1040 & $-0,1$ & - \\
\hline
\end{tabular}


Cizelge 13. Remlowcast $70 \mathrm{Zr}$ vibration castable numunesinin teknik özellikleri

\begin{tabular}{|l|c|}
\hline Servis sıcaklığ 1 & $1760^{\circ} \mathrm{C}$ \\
\hline Yumuşama sıcaklığ 1 & $39^{\circ} \mathrm{C}$ \\
\hline Kuru malzeme ihtiyacı & $2,8 \mathrm{~kg} / \mathrm{dm}^{3}$ \\
\hline Katılacak su miktarı & $\% 5-5,5$ \\
\hline $816^{\circ} \mathrm{C}$ 'de porozite & 18,7 \\
\hline Çalışma süresi & en fazla 90,120 dakika \\
\hline
\end{tabular}

\subsubsection{Remlowcast 60 SİC 30 Vibration Castable}

$75 \times 75 \times 75$ mm'lik kalıplara döküldükten sonra $1100^{\circ} \mathrm{C}$ 'de pişirilen Remlowcast 60 SİC 30 vibration castable refrakter tuğla numunesinin fizikomekanik özellikleri Çizelge 14'de ve teknik özellikleri ise Çizelge 15 'de verilmiştir.

Remlowcast 60 SİC 30 vibration castable numunesi 31 SİC ihtiva ettiği için yüksek mukavemete sahiptir. $\mathrm{Fe}_{2} \mathrm{O}_{3}$ oranı düşük olduğu için erozyon ve aşınmaya karşı yüksek mukavemet gösterir ve yük altında sicakta deformasyonun en az olması istenen yerlerde kullanımı uygundur. Yüksek yoğunluklu, düşük poroziteli ve çok yüksek mukavemet değerlerine sahip bir malzeme olmasının nedeni bünyesindeki su miktarının azlığıdır. $\quad 110-1350^{\circ} \mathrm{C}$ arası servis sıcaklığına sahiptir.

Cizelge 14. Remlowcast 60 SIC 30 vibration castable numunesinin fizikomekanik özellikleri

\begin{tabular}{|c|c|c|c|c|}
\hline $\begin{array}{c}\text { Sicaklık } \\
\left({ }^{\circ} \mathrm{C}\right)\end{array}$ & $\begin{array}{c}\text { Kırılma Modülü } \\
\left(\mathrm{kg} / \mathrm{cm}^{2}\right)\end{array}$ & $\begin{array}{c}\text { Basma Mukavemeti } \\
\left(\mathrm{kg} / \mathrm{cm}^{2}\right)\end{array}$ & $\begin{array}{c}\text { Kalıcı Boyutsal } \\
\text { Değişme }(\%)\end{array}$ & $\begin{array}{c}\text { Termal Kondüktivite } \\
\left(\mathrm{kcal} /{ }^{\circ} \mathrm{C} . h . m\right)\end{array}$ \\
\hline 110 & 110 & 700 & - & - \\
\hline 820 & 120 & 850 & - & - \\
\hline 1100 & 130 & 1100 & $-0,15$ & 2,8 \\
\hline 1250 & 140 & 1300 & -0.2 & - \\
\hline 1350 & 105 & 800 & $-0,3$ & \\
\hline
\end{tabular}

Çizelge 15. Remlowcast 60 SİC 30 vibration castable numunesinin teknik özellikleri

\begin{tabular}{|l|c|}
\hline Servis sıcaklığ 1 & $1370^{\circ} \mathrm{C}$ \\
\hline Yumuşama sıcaklığ1 & $25^{\circ} \mathrm{C}$ \\
\hline Kuru malzeme ihtiyac1 & $2,5 \mathrm{~kg} / \mathrm{dm}^{3}$ \\
\hline Katılacak su miktarı & en fazla $\% 5$ \\
\hline $816^{\circ} \mathrm{C}^{3}$ de porozite & 15 \\
\hline Çalışma süresi & en fazla 90,120 dakika \\
\hline
\end{tabular}

\subsubsection{Ultrasonik Test}

Refrakter tuğlalara yapısal özelliklerinin belirlenmesi ve pişme sırasında bünyesinde oluşan boşlukların tespiti amacıyla P-dalgası uygulanmış ve elde edilen sonuçlar Çizelge 16'da verilmiştir.

Çizelge 16. Ultrasonik testi deney sonuçları $(\mathrm{km} / \mathrm{sn})$

\begin{tabular}{|l|l|}
\hline Remlowcast 50 vibration castable & 3,857 \\
\hline Remgun 60 SİC 10 GG gunning castable & 3,003 \\
\hline Remlowcast 75 vibration castable & 4,066 \\
\hline Remlowcast 70 SİC vibration castable & 4,720 \\
\hline Remlowcast 70 Zr vibration castable & 4,411 \\
\hline Remlowcast 60 SİC 30 vibration castable & 3,468 \\
\hline
\end{tabular}

Çizelge 16'da yer alan ultrasonik test deney sonuçları incelendiğinde Remgun 60 SİC $10 \mathrm{GG}$ gunning castable, Remlowcast 60 SIC 30 vibration castable ve Remlowcast 50 vibration castable refrakter tuğlalarının P-dalgası değerlerinin diğer tuğlalara göre daha düşük olduğu görülmüştür. Gözlenen düşük P-dalgası değerlerinin tuğlaların pişmesi esnasında oluşan gözeneklerden kaynaklandığg düşünülmektedir.

\section{SONUÇLAR}

Yapılan çalışma kapsamında, refrakter tuğla üretiminde kullanılan malzemelerin kimyasal ve mineralojik özellikleri belirlenmiş; ardından hammaddeler ve değişik katkı maddeleri kullanılarak üretilen tuğlaların kimyasal, mineralojik, mekanik ve teknolojik özellikleri yapılan analizler ve deneyler ile incelenmiştir.

Toz refrakter hammaddelerin kimyasal analiz sonuçları örneklerin yüksek saflıkta olduğunu ve refrakterlik derecesini düşürecek alkali ve toprak alkali oksitlerin minimum seviyede bulunduğunu 
göstermiştir. Örneklerin kil veya şamot tuğla, silika, korundum veya korund tuğla, disten veya boksit olabileceği; mineralojik inceleme sonucuna göre örneklerin kil, silika, kil katkılı korund, boksit katkılı korund ve boksit olabileceği sonucuna varılmıştır. İncelenen örnekler ve eklenen katkılar değişik oranlarda karıştırılarak refrakter tuğla üretimi için uygun harçlar oluşturulmasına olanak sağlandığı anlaşılmıştır.

İncelenen refrakter tuğlaların $>\% 50 \quad \mathrm{Al}_{2} \mathrm{O}_{3}$ ihtiva etmesi nedeni ile sıcaklık şoklarına dayanabilecek yüksek mukavemete sahip olacağ1 düşünülmektedir. $\mathrm{Fe}_{2} \mathrm{O}_{3}$ oranının düşük olması tuğlaların erozyon ve aşınmaya karşı yüksek mukavemet sergileyeceğini göstermiş; yük altında sicakta deformasyonunun en az olması istenen firın bölgelerinde kullanımının uygun olacağı sonucuna varılmasını sağlamıştır.

$110^{\circ} \mathrm{C}, 820^{\circ} \mathrm{C}$ ve $1100^{\circ} \mathrm{C}$ sıcaklıklarda pişirilmiş refrakter tuğlalar üzerinde yapılan tek eksenli basma dayanım belirleme deneylerinde, incelenen numunelerden Remlowcast 75 vibration castable ve Remlowcast 70 SIC vibration castable adl numunelerin tek eksenli basma mukavemetlerinin diğer numunelere oranla daha yüksek olduğu tespit edilmiştir. Elde edilen değerlerden korund tuğlanın yüksek sıcaklıklarda sıvı gaz miktarı düşerek kristal oluşumu sağlanması ile yük altında refrakterliğinin arttığı, ergimiş silika tuğlanın hiç devitrifikasyona uğramadan kuvarsın modifikasyonları sırasında yoğunluklarının değişmesi nedeni ile yavaş soğutulması gerektiği anlaşılmıştır.

Ultrasonik test deney sonuçları incelendiğinde Remgun 60 SİC 10 GG gunning castable, Remlowcast 60 SIC 30 vibration castable ve remlowcast 50 vibration castable refrakter tuğlalarının P-dalgası değerlerinin diğer tuğlalara göre daha düşük olduğu görülmüştür. Gözlenen düşük p-dalgası değerlerinin tuğlaların pişmesi esnasında oluşan gözeneklerden kaynaklandığ 1 düşünülmektedir.

Deneyler sonucunda incelenen örneklerin iyi kalite refrakter olduğu sonucuna varılmıştır.

\section{KAYNAKLAR}

1. Geçkinli, A.E., 1992. İleri Teknoloji Malzemeleri, İstanbul Teknik Üniversitesi Matbaası Gümüşsuyu.

2. Kuşoğlu, İ.M., 2004. İleri Teknik Seramik Üretimi, Dokuz Eylül Üniversitesi Fen Bilimleri Enstitüsü Metalurji ve Malzeme Mühendisliği Anabilim Dalı Yüksek Lisans Tezi, İzmir, s. 111.

3. Tümer, M., 2004. Silisyum Nitrür Tozu Üretimi ve Sinterlenmesi, Selçuk Üniversitesi Fen Bilimleri Enstitüsü, Metal Eğitimi Anabilim Dalı Yüksek Lisans Tezi, Konya, s. 110.

4. Karabaș, K., 2006. Bor Karbür Üretimi, Dokuz Eylül Üniversitesi Fen Bilimleri Enstitüsü Metalurji ve Malzeme Mühendisliği Anabilim Dalı Yüksek Lisans Tezi, İzmir, s. 82.

5. DPT, 2001. Endüstriyel Hammaddeler Alt Komisyonu Toprak Sanayi Hammaddeleri III (Kuvars kumu-Kuvarsit-Kuvars) Çalışma Grubu Raporu, Ankara.

6. DPT, 2006. Dokuzuncu Kalkınma Planı (20072013), Taş ve Toprağa Dayalı Sanayiler Özel İhtisas Komisyonu Refrakter Sanayii Ön Raporu, Ankara.

7. Yarbil, S., 2012. Refrakter Tuğla Üretiminde Kullanılan Hammaddelerin ve Refrakter Tuğlaların Bazı Teknolojik Özelliklerinin İncelenmesi, Çukurova Üniversitesi Fen Bilimleri Enst., Maden Mühendisliği Anabilim Dalı Yüksek Lisans Tezi, Adana, s. 87. 
